\title{
Guidelines for the security of rare book, manuscript, and other special collections: A draft
}

\author{
Prepared by the ACRL Rare Books \& Manuscripts Section's Security Committee
}

\section{Abstract}

In a climate where theft of special collections materials is an everyday possibility, security must be a major concern of the entire library and special collections communities, with special collections administrators addressing it to the best of their abilities within their institutional context.

The ACRL/RBMS Security Committee's Guidelines for the Security of Rare Book, Manuscript, and Other Special Collections, published here, is the principal ACRL document dealing with the security of library materials. These guidelines identify important topics that collection administrators should address in developing adequate collection security. While directed primarily toward rare books, special collections, and manuscripts, the topics are also applicable to general collections. The RBMS Security Committee strongly urges implementation of these guidelines, including the unique identification marking of materials and the appointment of a Library Security Officer (LSO).

\section{Introduction}

These guidelines identify important topics that collection administrators should address in developing adequate collection security. While directed towards special collections, the topics are also applicable to general collections.

Administrators of rare book, manuscript, and special collection materials must insure that their collections remain intact and secure from theft and damage. The security of collections is now especially important since administrators' efforts to increase the use and knowledge of collections in their care can result in a greater public awareness of their value and may increase the risk of theft. Security arrangements vary from one institution to another and are dependent on staffing, physical setting, and use.

Rare book and manuscript dealers also must concern themselves with collection security, since thieves may offer stolen materials to them for sale. Librarians should make every effort to familiarize such dealers with the ways institutions attempt to secure and identify their materials and help them use this knowledge to lessen anyone's chances of profiting from theft.

The appointment of a LSO and the development of a security policy can help insure that staff are aware of their legal and procedural responsibilities in applying security measures.

\section{The library security officer}

Each institution concerned with the security of rare books, manuscripts, or other special collections materials should appoint a LSO. The LSO should be appointed by the library director, should have primary authority and responsibility to carry out the security program, and should have a thorough knowledge of all repository security needs, particularly those of special collections. The identity of the LSO should be widely known, especially among other administrative officers of the repository. The LSO's principal responsibility should be to plan and administer a security program, which should include a survey of the collections, reviews of the physical layout of the institution, and train- 
ing of the institution's staff. He or she should develop active working relationships with colleagues and seek the advice and the assistance of appropriate personnel, such as institutional administrators, corporate counsel, life safety officers, the LSO mail lists, and/ or outside consultants from law enforcement agencies and insurance companies.

\section{Suggestions for implementation}

1. In some repositories, the LSO and the special collections librarian may be the same person.

2. Special collections administrators in institutions without another official for whom the role of LSO would be appropriate are encouraged to take on this role and advocate that the institution recognize the importance of this responsibility within the institutional structure.

\section{The security policy}

The LSO should develop written policy on the security of the collections. In developing the policy, the LSO should consult with administrators and staff, legal authorities, and other knowledgeable persons. The policy should include a standard operating procedure on dealing with a theft or other security problems. The ACRL/RBMS Security Committee's document, "Guidelines Regarding Thefts in Libraries," provides steps to pursue in establishing adequate policies for dealing with thefts. The security policy should be kept up-to-date with current names and telephone numbers of institutional and law enforcement contacts. The institution should also review the policy periodically to insure that institutional needs continue to be adequately addressed. The LSO should not necessarily be conceived of as the library's general security officer, although he or she may also hold that role. The LSO should cooperate with and be involved with development and implementation of general library security measures, as these may affect the security of special collections materials. The LSO should also be involved with any library emergency and disaster planning.

\section{Suggestions for implementation:}

1. In larger institutions it may be necessary to assemble a security planning group to assist the LSO in identifying problem areas and to recommend solutions.
2. Institutions that lack appropriate staff resources may wish to bring in a security consultant to assist in developing a policy and in determining any major threats to the collection. When engaging a security consultant, the institution or LSO should use caution in evaluating the consultant's competence or ability to perform the work. The institution should investigate the security consultant's background and references thoroughly.

\section{The special collections building or area}

The special collections building or area should have as few access points as possible, with a single entry and exit point for both researchers and staff. Fire and emergency exits, which should be strictly controlled and provided with alarm coverage, should not be used for regular access.

Within the facility itself, the public should have access only to public areas, not to work areas or stack space. Researchers should be received in a separate reception area where a coat room and lockers should be provided for researchers' personal belongings and outer wear. A secure reading room where researchers can be continuously monitored by staff trained in surveillance should be identified as the only area in which material may be used. A security guard should check researchers' research materials prior to their entering the secure area as well as when they depart.

Keys and their equivalents, such as keycards, are especially vulnerable items; therefore, a controlled check-out system for all keys should be maintained. Keys to secure areas should be issued to staff only on an as-needed basis, and master keys should be secured against unauthorized access. Combinations to vaults also should have limited distribution and should be changed each time there is a staff change involving a position with access to the vault. Strong consideration should be given to installing proprietary keyways in locks in the special collections area. (See Ronald L. Libengood and Bryan J. Perun, "The Key to Good Security: Proprietary Keyways and Electronic Locks," Focus on Security, 2 [April 1995]: 6-16.)

\section{Suggestions for implementation:}

1. In institutions where it is not possible to hire an extra security guard, a staff mem- 
The "Guidelines for the Security of Rare Book, Manuscript, and Other Special Collections" began in 1978 with an ad hoc charge to the Rare Book and Manuscripts Section's (RBMS) Security Committee to develop guidelines for marking rare materials. Those marking guidelines were separately published in 1979 and when the present guidelines were originally published in 1982, the marking guidelines became an appendix to that document, a position they continue to occupy in the present document. The guidelines themselves were revised in 1990, and their publication here represents their third iteration.

When requested by ACRL in 1995 to review the guidelines, the RBMS Security Committee felt that it was an appropriate time to revise them to a great extent. Awareness of security issues in both the special collections and general library worlds indicated that certain aspects of the 1990 publication needed to be modified and made more current. Working under the direction of the RBMS Security Committee, a subcommittee headed by Nancy Romero began the work of revising the document, a task that took them nearly two years. After they presented their proposed revisions,

ber could perform this function. Consideration should also be given to installing a video surveillance system.

2. As a precautionary policy, keys and locks to secure areas should be changed on a regular basis.

3. When an institution plans to remodel or renovate space or to build a new facility in which special collections materials are to be housed, the LSO and the special collections administrator should ensure that all security needs are addressed in the design and planning.

\section{The staff}

An atmosphere of trust and concern for the collections is probably the best guarantee against theft by staff. Nevertheless, close and equitable supervision is essential. The staff, including students and volunteers, should be chosen carefully, using any and all avenues available in making the decision for hiring. Careful personnel management is an ongo- the entire RBMS Security Committee worked with the document for nearly another two years before it took its present form. A seminar was held at the RBMS Preconference in Washington, D.C., in 1998 wherein the proposed revisions were extensively discussed in that public forum. The document was also submitted to ACRL's Standards and Accreditation Committee for its review, and their comments were incorporated, as well. The RBMS Security Committee has also sought comment from other colleagues in the antiquarian book and manuscript trade, in the archival profession, and in other interest groups, both by appeals to individuals for comments and by postings to electronic discussion lists. At the ALA 1999 Midwinter meeting, a public hearing was held on the document; after that hearing the RBMS Executive Committee approved a recommendation that the guidelines be endorsed by that committee and be allowed to go forward.

After publication here, another hearing will be held at the ALA 1999 Annual Meeting in New Orleans (Saturday, June 26, from 11:30 a.m.-12:30 p.m.), after which final approval (continued on next page)

ing necessity. A weak point in maintaining a security system is disgruntled staff who may seek retribution through theft, destruction, or willful mishandling of collections. Consideration should be given to bonding employees who work in special collections.

Training the staff in security measures should be a high priority of the LSO. Such training should ensure that staff be aware of their legal and procedural responsibilities in relation to security as well as their own and the researchers' legal rights when handling possible problems. (See also the ACRL/RBMS "Standlards for Ethical Conduct of Rare Book, Manuscript, and Special Collections Libraries and Librarians, with Guidelines for Institutional Practice in Support of the Standards.")

\section{Suggestions for implementation:}

1. The LSO and special collections administrator should ensure that all staff are familiar with these guidelines and the security poli- 
for the document will be sought from ACRL and ALA

One significant feature in the present revision is Appendix II, "Addresses for Reporting Thefts." Because this document is mounted on the RBMS homepage, all of the URL's and e-mail addresses in that section will be "active" from the homepage. In other words, by looking at the electronic version on the Web page, a user may from that page simply follow the URL's to directly reach agencies to whom thefts should be reported. It is envisioned that these links will be periodically tested by the RIBMS Security Committee to ensure they are correct and that the text may be altered from time to time between formal revisions to ensure its currency and usefulness.

Another new feature of this revision is the incorporation of sections entitled "Suggestions for Implementation." These sections were added to give, in broad strokes, some practical guidance for implementing the recommendations found in the document, especially for staff in smaller repositories. Finally, Appendix I, the "Marking Guidelines," have been extensively revised and have been the subject of numerous lively debates both in the committee itself and in public meetings about the document.

cies in their institutions and how they may apply specifically to their institution.

2. When appropriate or consistent with institutional policies, background checks and bonding of staff members should be considered.

3 . The LSO or special collections administrator should be familiar with the institution's personnel policies, and advocate security concerns with the institution's human resources staff.

\section{The researchers}

The special collections administrator must carefully balance the responsibility of making materials available to researchers against the responsibility for ensuring the security of the materials. Staff must be able to identify who has used which materials by keeping adequate, signed check-out records, which should be retained indefinitely

Registration for each researcher who uses special collections materials should be required, recording the name, address, signa-
It should be emphasized that these guidelines do not stand alone and should be used in conjuncrion with other related RBMS guidelines, which are listed in Appendix III. The RBMS Security Committee is ready and eager to assist libraries in implementing the security recommendations in any of the guidelines.

People too numerous to mention have made contributions to these guidelines, and the continuing support and counsel of ACRL's Standards and Accreditation Committee in a time of transition have been crucial.

The present members of the RBMS Security Committee are: Everett C. Wilkie Jr., chair; Susan M. Allen (ex officio); Thomas L. Amos; Daren Callahan; Melissa Conway; Rachel Doggett; Connell B. Gallagher; Isaac Gewirtz; Rachel J. Howarth (intern); Anne Marie Lane; Katherine Keyes Leab; Ronald Liberman; Heather Lloyd; Michael North; Nancy Romero; Daniel J. Slive; and Diana M. Smith (intern).

Those wishing to comment on the guidelines should send comments to Everett Wilkie at ewilkie@ix.netcom.com and/or plan to attend the hearing in New Orleans on Saturday, June 26, from 11:30 a.m.-12:30 p.m. (venue to be announced later).-Everett Wilkie, euilkie@ix.netcom.com

ture, institutional affiliation (if any), and photo identification or some other form of positive identification to establish physical identity. These registration records should be retained permanently.

Researchers should be required to present a reasonable explanation of their need to use the materials. Each researcher should be given an orientation to the collections requested and to the rules governing the use of the collections. Researchers should not be permitted to take extraneous personal materials into the reading areas. This includes such items as notebooks, briefcases, outer wear, books, and voluminous papers. Personal computers should be removed from the case before use in the reading room is permitted. Lockers or some kind of secure space should be provided for any items not permitted in the reading room.

Staff should observe researchers at all times and not allow them to work unobserved behind bookcases, book trucks, 
stacks of books, or any other obstacles that restrict staff view. Researchers should be limited at any one time to having access only to those books, manuscripts, or other items that are needed to perform the research at hand. Staff should check the condition, content, and completeness of each item prior to giving it to the researcher and also when it is returned after use. This checking of materials that are returned is especially important for the use of archival and manuscript collections, which often consist of many loose, unique pieces. Researchers should be required to return all library materials prior to leaving the reading room, even if they plan to return at a later time to continue their research. Researchers should not be allowed to exchange materials or to have access to materials brought into the room for use by another researcher.

\section{Suggestions for implementation:}

1. The LSO or special collections administrator should seek the advice of the institution's legal counsel or other appropriate legal authority when developing researcher policies, to ensure adequate legal recourse if researchers violate the use agreement.

2. The institution should require that all researchers read and sign an agreement to abide by institutional policies. This agreement should be renewed annually.

\section{The collections}

Administrators of special collections must be able to identify positively the materials in their collections to establish loss and to substantiate claims to recovered stolen property. This includes keeping adequate accession records; maintaining detailed cataloguing records and lists in finding aids; recording copy-specific information; and keeping condition reports and records. Lists developed to fulfill the requirements of insurance policies should also be kept current. In addition, the materials themselves should be made identifiable. This can be accomplished by marking them following the RBMS "Guidelines for Marking" (see Appendix I), by applying other unique marks, and by keeping photographic or microform copies of valuable items.

\section{Suggestions for implementation:}

1. More valuable items should be segregated from the collections into higher secu- rity areas, with more restricted conditions for staff access and researcher use.

2. If appropriate security controls are applied, unprocessed materials may be made available to researchers for short-term use.

\section{Transfers from the general collection}

Many institutions house materials in open stack areas accessible to all users. These open stack areas may contain rare materials, which remain unidentified and unprotected. Materials in open stack areas are most vulnerable to breaches in security. Many thieves search open stacks areas for materials considered rare, rather than attempt to infiltrate special collections areas or outwit the security measures implemented in monitored reading areas. Institutions should establish procedures for the routine areas, using the ACRL/RBMS "Guidelines on the Selection of General Collection Materials for Transfer to Special Collections" to assist in identifying rare materials on the open shelves in need of protection.

\section{Legal and procedural responsibilities}

The administrators of special collections and the LSO must know the laws for dealing with library theft that are applicable in their state and must convey this information to staff. Staff members must be aware of their legal rights in stopping thefts and not infringing on the rights of the individual suspected of theft.

The administrator of special collections and the LSO must report thefts of rare materials to appropriate law enforcement agencies and must take responsibility for requesting action from legal authorities. The theft of materials, whenever the theft is discovered, must be reported in a timely manner to help prevent the unknowing transfer of the items and to facilitate their return. Appropriate agencies to report to include local, institutional, and state law enforcement agencies and the Federal Bureau of Investigation. Consult Appendix II for reporting details. For legal and procedural responsibilities, see "Guidelines Regarding Thefts in Libraries" (listed in Appendix III).

\section{Suggestions for implementation}

1. LSOs and/or special collections administrators should take an active role in raising 
the awareness of other institutional officials, e.g., institutional legal officers, public safety officers, the library director, etc., regarding the serious nature of materials theft. and urge the institution to actively seek the resolution of security threats and breaches and to seek the strictest punishment possible for those convicted of theft or other security violations.

\section{Conclusion}

The guidelines presented here are necessar- ily brief since further information is available through professional literature, professional organizations, and consultants within the rare book, manuscript, and special collections community, and in the law enforcement and insurance professions. The effort of the entire staff, with final responsibility vested in one senior staff member, working in cooperation with law enforcement, will result in more secure collections wherein materials are preserved and macle available for all who wish to use them.

\section{Appendix I}

\section{Guidelines for marking books, manuscripts, and other special collections materials}

\section{Introduction}

There has been much thoughtful discussion regarding the appropriateness of permanently marking books, manuscripts, and other special collections materials. Failure to mark compromises security. Cases of theft show that clear identification of stolen material is vital if material, once recovered, is to be returned to its rightful owner. The following guidelines are intended to aid libraries and other institutions in marking their materials and to provide as consistent and uniform a practice as possible.

Even the most conservative marking program results in permanent alteration of materials. Choices concerning marking are likely to depend heavily on one's aesthetic judgment balanced against the need to secure materials from theft and to assist in their identification and recovery. Each repository will have to balance those competing needs. The ACRL/RBMS Security Committee recommends that libraries and other institutions use marking as part of their overall security procedures and that they attempt to strike a balance between the implications for deterrence (visibility, permanence) and the integrity of the documents (both physical and aesthetic).

\section{General recommendations}

General recommendations are:

A) That markings be of two types:

1) readily visible to the casual observer, and

2) hidden and difficult to detect.

B) that readily visible marks be made in an approved form of permanent ink.
C) that marks which are hidden or difficult to detect never be the only or primary types of marking.

D) that visible marks be placed so that they will cause significant damage to the aesthetic and commercial value of the item if they are removed.

E) that marks be placed directly on the material itself and not on an associated part from which the material may be separated.

F) that all marks unequivocally and clearly identify the repository.

\section{Discussion}

A) Readily visible marks are intended to deter potential thieves; hidden marks are intended to assist in the recovery of stolen materials. If only one type of mark is to be used, it should be of the readily visible type. The size should be kept to a minimum (ca. 5 point type size for lettering).

B) Visible marks should be all but impossible to remove and should never consist of just a bookplate. Although not the only form of a visible mark, ink is perhaps the best medium for this purpose, so long as the ink meets current standards for permanence and conservation. There is still controversy surrounding which inks are best suited for this purpose, so a recommendation cannot go beyond urging those in charge of marking programs to be current on the latest developments in this field.

C) Hidden marks should never be used as the only form of marking, because they are worthless in alerting others, such as booksellers, that material has been stolen. Hidden marks are intended only as supplements to visible marks. 
D) Much controversy has surrounded the placement of visible marks. Given the varying nature of special collections materials and the varying nature of beliefs and sentiments concerning what is proper placement for a visible mark, it is probably futile to overly prescribe placement of marks. It is recommended, however, that no position for a mark be rejected outright. Some repositories might, for example, be comfortable stamping the verso of a title page or the image area of a map; others might reject those options. But no matter where the visible mark is placed, it should not be in a position that it can be removed without leaving quite obvious evidence of its former presence.

Some items do present unusual decisions on placement of visible marks. The following are specific recommendation for the formats listed.

1. Medieval and Renaissance Manuscripts, Incunabula, and Early Printed Books: On the verso of the first leaf of principal text, on the lower inner margin, approximate to the last line of text. Additional markings may be needed when the item is a composite manuscript or otherwise has a substantial text that may be broken away without noticeable injury to the volume. The location of each subsequent marking would be the same; i.e., lower inner margin approximate to the last line of text.

When the item is too tightly bound to mark in the inner margin, alternate locations may be made in any blank area of the verso, as close to the lower portion of text as possible. The mark should be so placed that it may not be excised without extreme cropping. (In items of double columns, the mark might be located in the blank area between the columns.)

\section{Leaf Books, Single Leaves from}

Manuscripts: On either verso or recto, at the lower portion of the text or image of each leaf. The choice may be determined by the document itself if one of the sides has more importance (owing to an illustration, manuscript notation, etc.) The ownership mark should then be placed on the reverse side.

E) Marks of whatever type must be placed directly on the material itself. Marks placed only on a front pastedown in a book, on a portfolio that holds prints, or on some type of backing material are rendered useless if that element is separated from the item. Especially in the case of flat items, such as maps and broadsides, it is important that the marks be applied before any backing procedure is done.

F) Marks should not be generic (e.g., "Rare Book Room," "Special Collections," "University Library," etc.), but should rather make plain the repository to which they refer. It is recommended that visible marking consist of the repository's Library of Congress symbol. If a repository lacks such a symbol, the Library of Congress will supply one upon request. If the Library of Congress symbol is not used, then the name of the repository should be used, being careful that no confusion arises among repositories with similar or identical names.

\section{Other considerations}

A) Hidden marks do not have to be marks at all. They merely have to provide some positive ownership indication that is extremely difficult if not impossible to detect. Microembossers, for example, provide an extremely cheap and difficult to detect type of nearly invisible mark. Modern technology also provides non-invasive marking techniques such as micro-photography that does not leave any mark on the item itself yet serves as positive identification. Other technologies, such as micro-taggants, may also be appropriate for this purpose. It is vital if such marks are used, however, that the repository keep extremely accurate records of such marks so that they can be readily found for identification purposes if the need arises to do so. Generic secret marking systems, such as underlining a word on p. 13 of every book, should be avoided as the sole means of such marks.

B) Repositories should never attempt to cancel marks, even in the event that the material is deaccessioned. No system has yet been devised for canceling marks that cannot be imitated with relative ease by thieves, and there seems to be no alternative but to assume permanent responsibility for one's mark on a book, manuscript, or other document. Permanent records should be kept of deaccessioned materials, whether marked or unmarked, and the material itself when released should be accompanied by a document conveying ownership. It is advisable to place stamps or notes in items indicating that they have been deaccessioned, but no attempt should be made to cancel or remove previous ownership marks. 
C) Marks should be applied to all items when they come into the repository. It is dangerous to send unmarked items into storage or a cataloguing backlog, where they may remain for years with no indication that the repository owns them. Despite the fact that some items may present extremely difficult and complicated decisions about marking, the process should never be deferred. It is strongly recommended that programs also be instituted to retrospectively mark materials already in the collections

D) Care must be taken to ensure that all discrete or removable parts are marked. It is recommended that each separate plate, map, chart, or other such item in a printed volume be marked individually. volumes of bound manuscripts and collections of individual manuscripts present a similar problem and each discrete item in such collections should also be marked.

E) Because marking should be part of an overall security program, the role of cataloguing in identifying materials should not be overlooked. Accurate and detailed physical descriptions that note anomalies, defects, provenance, and unusual physical characteristics are essential adjuncts to ownership markings.

\section{Appendix II}

\section{Addresses for reporting thefts:}

(Kept current and interactive at http:// www.princeton.edu/ ferguson/secguide. html.)

- AB Bookman's Weekly, Missing Books Section. P.O. Box AB, Clifton, NJ 07015. (201) 772-0020; fax: (201) 772-9281.

- Antiquarian Booksellers Association of America, 20 West 44th St., 4th floor, New York, NY 10035-6604. (212) 944-8291; fax: (212) 944-8293; e-mail: abaa@panix.com. Homepage for theft reporting: http:// www.abaa-booknet.com/stolen.htm

- ACRL/RBMS Security Committee, c/o American Library Association, $50 \mathrm{E}$. Huron St., Chicago, IL 60611. (800) 545-2433, ext. 2516; fax: (312) 440-9374; e-mail: ala@ala.org. ALA homepage: http://www.ala.org; RBMS homepage: http://www.princeton.edu/ $\sim$ ferguson/rbms.html.

- Society of American Archivists, 527 S. Wells, Chicago, IL 60607. (312) 922-0140, fax:
(312) 347-1452; e-mail: sfox@archivists.org Homepage: http://www.archivists.org. Security list (moderated and open to SAA members only): saasecurityrt-1@cornell.edu.

- Professional Autograph Dealers Association, c/o Catherine Barnes, P.O. Box 30117, Philadelphia, PA 19103. (215) 8540175; fax: 215-854-0831; e-mail: cbarnes2@ ix.netcom.com; homepage: http://www padaweb.org. Toll free: (888) 338-4338 (U.S. only).

- Library Security Officer Electronic List, Susan Allen, head, Department of Special Collections, URL-Room A1713, Box 951575 , UCLA, Los Angeles, CA 90095-1575. (310) 825-2422; fax: (310) 206-1864; send reports to: sallen@library.ucla.edu.

- ExLibris Electronic Discussion List exlibris@library.berkeley.edu (unmoderated, but must be a member to post).

- Interloc. http://www.interloc.com/lost/ index.htm. Reporting address: interloc@ interloc.co.

- Museum Security Network; http://museum-security.org; reporting address: securma@pop.xs4all.nl.

- Archives \& Archivists Electronic Discussion List: archives@listserv.muohio.edu.

- ReRicci Project: dericci@aol.com (for pre-1600 manuscripts only).

\section{Appendix III \\ Related guidelines:}

(ACRL documents available at: http:// www.ala.org/acrl/guides/index.html.)

- Association of College \& Research Libraries. Guidelines Regarding Thefts in Libraries (1994).

- Association of College \& Research Libraries. Guidelines on the Selection of General Collection Materials for Transfer to Special Collections (2nd ed. 1994).

- Association of College \& Research Libraries. Standards for Etbical Conduct of Rare Book, Manuscript, and Special Collections $L i-$ braries and Librarians, with Guidelines for Institutional Practice in Support of the Standards (2nd ed. 1992).

- Society of American Archivists. Libraries and Archives: An Overview of Risk and Loss Pretention (1994).

- Society of American Archivists. Protecting Your Collections: A Manual of Arcbival Security (1995) 


\section{w w w. womensperiodicals.ps media.com}

selection of women's journals,
newspapers and magazines from
Primary Source Media's History of Women microfilm collection is now available online! Scholars and researchers on all levels can achieve faster, easier and more flexible access to a world class resource in women's studies. Search, access and evaluate women's issues through first hand accounts in the most significant periodical database of its kind.

Written primarily for women by both men and women during the mid 1800 s through 1920 s, these periodicals deliver diverse opinions about the roles of women in society and business. Suffrage and anti-suffrage writing, domesticity columns, and literary genres from poetry to serialized novels are included in these periodicals.

Interpret social, political, economic, and literary matters, internationally, through history. Assess the connotations of the advertisements, letters to the editors, articles, stories and poems. Study the definitions, roles, and perceptions of and about women, culture, and politics.

\section{Efficient Access}

The full text of every periodical has been keyed, allowing specific word, phrase, name or date searchability. Special search fields provide more targeted document retrieval options. Easily accessible digital facsimiles can be downloaded and printed as required. Both IP address verification and password protection registration options are available.

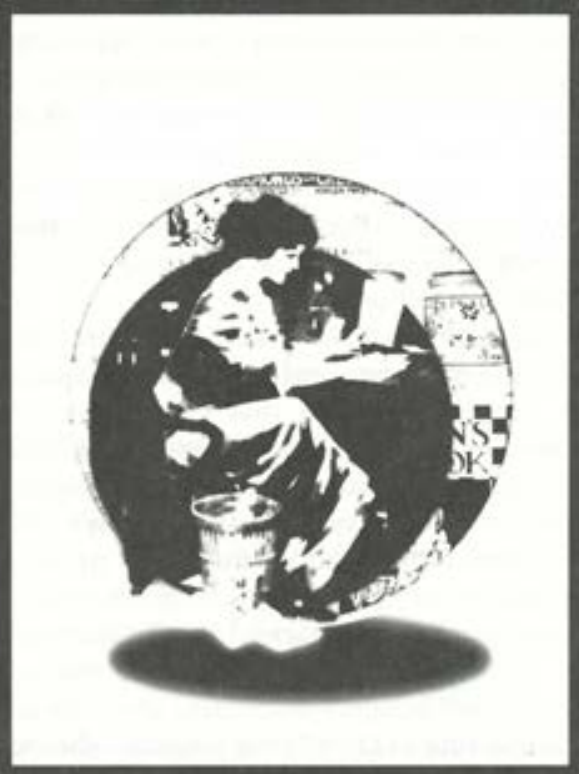

WOMEN'S STUDIES ARCHIVES:

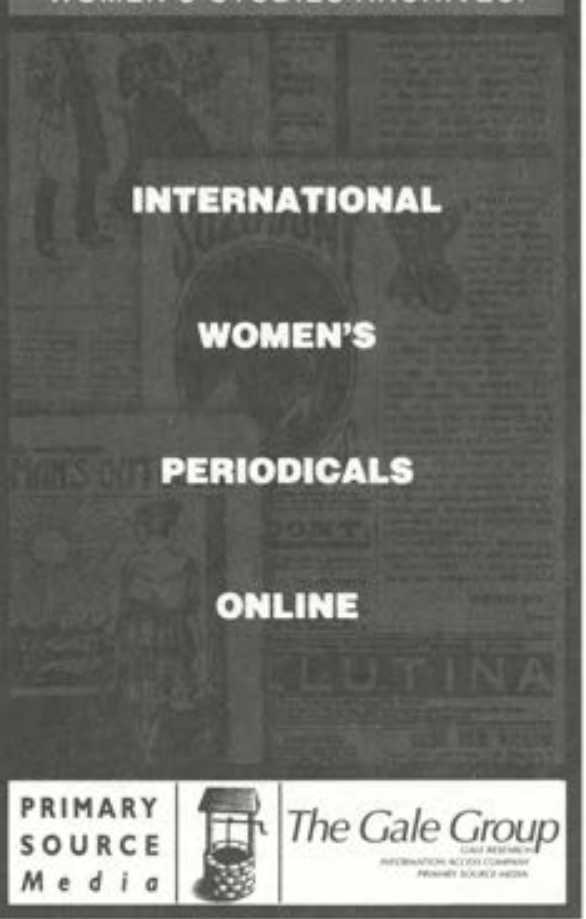

